\title{
Mapping human impact on Net Primary Productivity using MODIS data for better policy making
}

\begin{abstract}
Tropical forests support core biological, hydrological and socioeconomic functions essential to life on earth. An assessment based on the Human Appropriation of Net Primary Production (HANPP) could help reduce exploitation of these forests, increasing their adaptive capacity and lessening their vulnerability to losses of Net Primary Productivity (NPP). Here we apply HANPP to the study area, based on Land Use Impact variability between the forest and contiguous roads and plantations by application of Geographical Information Systems of Protected Area Tools. We used the human activity index and biomass extraction from forest to study the effects of population pressure. The final land use impact map showed that the largest area of forest land (37\%) is now in urban and agricultural use, and that these areas are located within 0-3 km of the forest land. NPP with human intervention showed, total NPP of the forest decreased by $7.4 \%$, from 104.4 to $96.6 \mathrm{gCm}^{-2}$ month ${ }^{-1}$. This study developed a new HANPP model and enhanced the usefulness of HANPP indicators by demonstrating the impact of human activity inside the forest. Because NPP changes most in higher-productivity areas, suitable policies should be enforced to avoid further human interference in the area.
\end{abstract}

Keyword: Human appropriation of NPP; Land use; Human; Population; NPP 